\title{
Identity and well-being of ethnic minority and mainstream adolescents in Bulgaria
} \author{
Fons J. R. van de Vijver ${ }^{3,5 \cdot A, C, D, E}$ \\ 1: Department of Psychology, Stockholm University, Sweden \\ 2: Department of Education, Hiroshima University, Japan \\ 3: Faculty of Social and Behavioral Sciences, Tilburg University, the Netherlands \\ 4: Gratia Christian College, Hong Kong \\ 5: North-West University, South Africa, and University of Queensland, Australia
}

Radosveta Dimitrova ${ }^{1,2 \cdot A, B, C, D, E, F}$, Athanasios Chasiotis ${ }^{3 \cdot A, D, E, G}$, Michael Bender ${ }^{4 \cdot A, D, E, G}$,

\section{BACKGROUND}

We study identity in the context of long-term sedentary groups in Eastern Europe in contrast to the frequently studied short-term immigrants in typical Western European or US American contexts. This paper provides a novel approach to youth identity in an Eastern European post-communist context for minority groups that are quite distinct from the mainstream group to advance the study of identity. Turkish-Bulgarians and Muslim-Bulgarians have been subjected to extensive assimilation campaigns, which prompted them to carefully negotiate their ethnic identity and sense of belonging.

\section{PARTICIPANTS AND PROCEDURE}

Participants were 366 adolescents aged 16 to 18 years $(M=16.72, S D=0.71)$ from South Central and South Western regions of Bulgaria. This sample included Turkish-Bulgarian $(n=145)$, Muslim-Bulgarian $(n=85)$, and (mainstream) Bulgarian $(n=136)$ youth who provided data on personal, ethnic, familial, and religious identity as well as psychological well-being.

\section{RESULTS}

Turkish-Bulgarian youth scored higher on achievement, diffusion, and foreclosure but lower on moratorium and Bulgarian ethnic and familial identity than Muslim-Bulgarian and Bulgarian youth. Bulgarian mainstreamers scored significantly lower on religious identity compared to their Turkish-Bulgarian and Muslim-Bulgarian peers. Finally, Bulgarian mainstream identity significantly predicted well-being of youth from all groups, independent of their ethnic background.

\section{CONCLUSIONS}

A strong ethnic and familial identity results in beneficial psychological outcomes for youth, even in the face of adversity and assimilation.

\section{KEY WORDS}

well-being; identity; minority adolescents; Bulgaria

CORResPonding AUthor - Radosveta Dimitrova, Ph.D., Department of Psychology, Stockholm University, Frescati Hagv 14, SE 10691 Sweden, e-mail: dimitrova.radosveta@gmail.com

AUthors' CONTRIBUtion - A: Study design - B: Data collection · C: Statistical analysis · D: Data interpretation .

E: Manuscript preparation · F: Literature search · G: Funds collection

to CITE this ARTICLE - Dimitrova, R., Chasiotis, A., Bender, M., \& van de Vijver, F. J. R. (2017). Identity and well-being of

ethnic minority and mainstream minority adolescents in Bulgaria. Current Issues in Personality Psychology, 5(1), 41-52.

RECEIVED 14.04.2016 · REVIEWED 10.05.2016 · ACCEPTED 27.05.2016 · PUBLISHED 09.12.2016 


\section{BACKGROUND}

This paper focuses on youth's collective identity in an Eastern European post-communist context in minority groups that are quite distinct from the mainstream group. Turkish-Bulgarians and Muslim-Bulgarians have been subjected to extensive assimilation campaigns (Dimitrov, 2000), which prompted them to carefully negotiate their ethnic identity and sense of belonging. Our main goal is to test whether various components of identity, namely identity status, ethnic, familial, and religious identities, are related to well-being in ethnic minority and mainstream youth in Bulgaria. We compared Turkish-Bulgarians and Muslim-Bulgarians to their mainstream Bulgarian peers so as to provide reference data for the widely investigated ethnic groups with a longer immigration history in the mainstream society, such as in the Unites States and European countries.

The current paper draws on the multidimensional definition of identity (Ashmore, Deaux, \& McLaughlin-Volpe, 2004) as comprising multiple categories, each of which can contribute to the well-being of youth. In so doing, we propose a procedure to study identity, which makes a distinction between aspects of collective identity, such as ethnic, familial and religious identity, and the development or status of identity. We chose these identity domains because existing literature suggests that across different cultural groups, identity formation plays a central role in facilitating social functioning and well-being (Phinney, 1990; Rivas-Drake et al., 2014; Smith \& Silva, 2011; Verkuyten \& Yildiz, 2009). Also, minority youth, compared to mainstream youth, display higher levels of ethnic, familial, and religious identity; a stronger identity in these three domains is associated with higher well-being (Furrow, King, \& White, 2004).

We follow a distinction between identity statuses and collective identity, in line with theory and research from developmental and social psychology. These perspectives have investigated identity and its relevance in young people's lives. Developmental theories focus on identity formation (Phinney, 1989 ) in terms of identity achievement (firm commitment after identity exploration) and identity diffusion (neither exploration nor commitment) (Erikson, 1968; Marcia, 1980). Social identity (Tajfel \& Turner, 2001) and self-categorization theories (Turner, Hogg, Oakes, Reicher, \& Wetherell, 1987) acknowledge the importance of societal context for identity formation. By drawing on developmental and social identity perspectives of identity, we investigate multiple identities relevant to the study of youth with different ethnic backgrounds in an underrepresented cultural context in Eastern Europe. In so doing, we define identity as the process of search and establishment of one's identity by finding an answer to the question "who am I?" as well as navigating among multiple social identities while integrating these in a meaningful and coherent sense of self (Crocetti, Fermani, Pojaghi, \& Meeus, 2011). We also refer to a widely used definition of well-being in established research in psychology and generally in well-being and happiness studies. These studies usually treat well-being as representative of life satisfaction and positive emotions. Well-being is conceptualized as having multiple empirical and conceptual facets, including global life satisfaction, positive experiences and beliefs about life as well as frequent positive emotions (Diener, Lucas, \& Scollon, 2006; Lucas, Diener, \& Suh, 1996).

\section{ETHNIC, FAMILIAL AND RELIGIOUS IDENTITY AND WELL-BEING}

The establishment of an ethnic identity is a central issue for adolescents as a means of maintaining positive feelings that accompany a sense of ethnic group belonging (Phinney \& Ong, 2007). The development of ethnic identity involves a process of exploration and commitment which can result in a secure and confident sense of identity (Ghavami, Fingerhut, Peplau, Grant, \& Witting, 2011). Across various ethnic groups, a strong sense of ethnic identity is associated with enhanced levels of well-being (Costigan, Koryzma, Hua, \& Chance, 2010; Yap, Settles, \& Pratt-Hyatt, 2011). Familial identity concerns the relevance of the familial group for the self and the importance assigned to a nuclear or extended family as a source of socio-emotional support (Bagger, Li, \& Gutek, 2008). A strong familial identity in ethnic minority groups is associated with positive adjustment (Vazsonyi \& Pickering, 2003) and health-protective behaviors against negative effects of stress (Cleveland, Feinberg, \& Greenberg, 2010). Finally, religious identity concerns the sense of group membership in relation to religious convictions and their importance for individual identity (Nesbitt \& Arweck, 2010). It has been found that religious identity is very strong among ethnic minority adolescents (Lopez, Huynh, \& Fuligni, 2011; Wallace, Forman, Caldwell, \& Willis, 2003). A strong religious identity fosters positive well-being, including low levels of disruptive behaviors (Udel, Donenberg, \& Emerson, 2011) and internalizing and externalizing problems (Bartowski, $\mathrm{Xu}$, \& Levin, 2008). Although identity research generally emphasizes the importance of ethnicity, family, and religion for identity formation (Schwartz, Zamboanga, Weisskirch, \& Rodriguez, 2009), there is very little empirical work on the religious correlates of identity status. Even less work has dealt with the interrelation of the identity components described above and their relation to well-being of ethnic minority youth, a gap this paper aims to address. 


\section{IDENTITY STATUS AND WELL-BEING}

Identity status. Most literature on identity status is predicated on the identity status paradigm (Erikson, 1968; Marcia, 1980; Schwartz, Luycks, \& Vignoles, 2011), which provides a classification of identity development according to four statuses derived from the combination of two basic processes: exploration and commitment. Exploration refers to the active consideration of one's opportunities for identity establishment, whereas commitment refers to the extent of personal involvement with self-chosen aspirations, values, and beliefs (Marcia, 1980; Schwartz et al., 2011). The combination of exploration and commitment generates four prototypical identity statuses: diffusion (neither engagement in exploration nor commitment), foreclosure (commitment made without exploration, e.g., consistent with parental values and the ways in which parents perceive their offspring), moratorium (exploration without commitment), and achievement (firm commitment after exploration).

Findings with regards to group differences in identity statuses between minority and mainstream youth are mixed. Some studies found that Mexican-American, Hispanic, African, and Asian minority youth more often hold a foreclosure status compared to their mainstream European-American peers (Spencer \& Markstrom-Adams, 1990; Streitmatter, 1988), whereas Turkish, Moroccan, and Surinamese youth in the Netherlands more often hold a moratorium status than Dutch mainstreamers (Crocetti, Rubini, Luyckx, \& Meeus, 2008). Other studies report that ethnic minority youth more often having a foreclosure status, whereas most of their mainstream peers were in moratorium (Watson \& Protinsky, 1991). Some studies report no ethnic group differences, for example in identity statuses displayed by EuropeanAmerican compared to African American, LatinoHispanic, Asian American samples, Puerto Rican, and Filipino adolescents (Branch, Tayal, \& Triplett, 2000). The findings are difficult to generalize due to the variety of ethnic groups and cultural contexts from which they derive. Moreover, it is uncommon to address potentially relevant contextual variables with a bearing on identity.

Findings on the relation between identity formation and psychological well-being are fairly consistent (Kroger \& Marcia, 2011). Overall, adolescents with an achievement or foreclosure status are characterized by better psychological outcomes than their peers holding a moratorium status, and individuals in the diffusion status exhibited lower adjustment levels compared to individuals in the other statuses (Luyckx, Goossens, Soenen, Beyers, \& Vansteenkiste, 2005). Recent conceptualizations of identity statuses have also argued for the potentially adaptive role of diffusion in relation to context resources that may provide the psychological balance that the diffusion status lacks (Kroger \& Marcia, 2011). In this line of reasoning, identity diffusion with a weak exploratory period and an inability to make definite commitments may be adaptive. Thus, diffusions can be whatever influences within the adolescent context shape them to be in the search for an internal sense of self-definition.

Specifically for minority youth, identity status plays a key role in the way they approach their cultural setting and deal with acculturation issues. Foreclosure status is generally associated with lower levels of well-being, whereas achievement, and to a lesser extent moratorium statuses, correlated positively with psychological functioning (Schwartz et al., 2009). For instance, in a large-scale multi-ethnic study in the Unites States, Schwartz and colleagues (2009) reported that personal identity exploration was strongly associated with both adaptive and maladaptive psychosocial functioning. Personal identity exploration was associated with lowered psychological well-being and with anxiety, depression, and impulsivity. The authors give a practical insight into their findings in that developing a sense of personal identity is essential for making one's way in the world and that lacking a coherent sense of personal identity through the identity exploration process may create a sense of aimlessness. Among other ethnic minority groups, adolescents with achieved identity have been found to report the highest self-esteem and lowest depression levels; adolescents in moratorium generally exhibit lower self-esteem and higher levels of depression and anxiety (Berman, Weems, \& Stickle, 2006); adolescents with a foreclosure status score lower than adolescents with achieved identity in self-esteem, and adolescents with a diffusion status scored lower on self-esteem and higher on measures of depression (Kroger \& Marcia, 2011). These findings bear relevant implications for implementation of interventions to promote personal identity development, to facilitate subjective well-being, and to reduce psychological distress in young people with a diverse ethnic background.

\section{AIMS, CONTEXT, AND HYPOTHESES}

This study was carried out in Bulgaria, which, like other Eastern European countries, is experiencing marked political and economic instability due to the shift from a communist to a capitalist economy. Bulgaria hosts relevant ethnic minority communities that have been present in the country for centuries, such as Turkish-Bulgarians and Muslim-Bulgarians.

Turkish-Bulgarians represent 605,802 of the total population of nearly 8 million people (National Statistics Institute, 2011) and inhabit mainly the South-Eastern parts of the country close to the Turk- 
ish-Bulgarian border. They are the largest ethnic minority group in the Christian Orthodox Bulgarian context, with a separate language (Turkish), religion (Islam), and culture that has existed in Bulgaria for centuries. This group has faced much discrimination and various assimilation attempts (Dimitrov, 2000). Muslim-Bulgarians are Bulgarians who converted to Islam during the Ottoman Empire (spanning from 1299 to 1923). Their group has been estimated to comprise between 80,000 and 269,000 people (Konstantinov, Alhaug, \& Igla, 1991) living in Southern Bulgaria. Similar to the Turkish-Bulgarians, MuslimBulgarians have faced assimilation campaigns and socioeconomic disadvantages (Srebranov, 2006).

Both these target minority groups have been compared to a sample of mainstream Bulgarians. The comparison of ethnic minority groups with their mainstream peers from the dominant society has the potential to unravel important cultural differences in identity and well-being. Ethnic minority communities are clearly defined in rigid patriarchal structures, whereas the dominant Bulgarian culture is much less patriarchal in comparison. Consequently, ethnic minority youth are raised and expected to fulfill traditional functions of their community, in contrast to their Bulgarian peers, who live in a much less traditional family context. In fact, in the dominant Bulgarian family setting, old traditional roles of family members are diminished, and equality between men and women strengthened (Georgas, Berry, van de Vijver, Kagitcibasi, \& Poortinga, 2006). Therefore, the ethnic minority groups in this study are quite distinct from the mainstream Bulgarian group. As sedentary long-term minorities they also differ from typical immigration receiving countries throughout the rest of Europe. Studying the relation between identity and well-being in such marginalized groups may contribute insights that will into how to foster positive psychological outcomes among young minority group members. We address the question of how adolescents negotiate their identity in the face of adversity.

Our first predictions regard group differences in identity status. Based on previous studies, we expect minority youth to more frequently hold a moratorium status (Hypothesis 1a) (Crocetti et al., 2008) and a foreclosed status (Spencer \& Markstrom-Adams, 1990) (Hypothesis 1b) than mainstreamers. Because Turkish-Bulgarian and Muslim-Bulgarian adolescents belong to two distinct minority groups, we also expect different patterns of ethnic, familial, and religious identity to emerge. First, we expect Turkish-Bulgarian youth to endorse their Turkish identity more strongly than their Bulgarian identity (Hypothesis 1c). This expectation is based on prior work highlighting the relevance of Turkish domains of identity and acculturation in Turkish ethnic minority groups in Europe (e.g., Germany and the Netherlands) as well as Bulgaria (Aydinli \& Dimitrova, 2015; Dimitrova,
Aydinli, Chasiotis, Bender, \& van de Vijver, 2015; Dimitrova, Chasiotis, Bender, \& van de Vijver, 2014a, 2014b). These studies generally show that across all these cultural contexts, Turkish groups regarded maintenance of their Turkish culture as more important than that of the host culture (e.g., Bulgarian, German, and Dutch) adoption. We do not expect such a pattern for Muslim-Bulgarians as their ethnic identity is Bulgarian, like the mainstream Bulgarians. Second, based on previous studies reporting on religious identity salience for Muslim minority groups (Verkuyten \& Yildiz, 2009), we expect Turkish-Bulgarian and Muslim-Bulgarian youth to more strongly endorse their religious identity than their Bulgarian peers, among whom a generally less pronounced religiousness is observed (Halman \& Petterson, 2001) (Hypothesis 1d).

Our second set of predictions involves associations between identity and well-being. Following prior work (Luyckx et al., 2005), we anticipate that an achievement or foreclosure status will relate to better psychological outcomes than a moratorium or diffusion status (Hypothesis 2a). Moreover, we expect ethnic, familial, and religious identities to be important predictors of well-being for youth (Hypothesis $2 b$ ).

\section{PARTICIPANTS AND PROCEDURE}

Participants were 366 adolescents aged 16 to 18 years $(M=16.72, S D=0.71)$, attending various schools in the South Central and South Western regions of Bulgaria. This sample included Turkish-Bulgarian $(n=145)$, Muslim-Bulgarian ( $n=85$ ), and (majority group) Bulgarian $(n=136)$ youth (Table 1$)$. The three groups did not differ with respect to gender $\left(\chi^{2}(2, N=366)=\right.$ 5.59, $p=.061$ ), but there were age differences, with Bulgarians being about four months younger than minority youth, $F(2,365)=5.28, p<.001$. Cultural groups differed with respect to family socioeconomic status $(\mathrm{SES})\left(\chi^{2}(4, N=361)=112.87, p<.001\right)$, with Bulgarian youth having a higher SES. All subsequent analyses controlled for these effects.

Prior to the data collection, local school authorities and parents were informed about the purpose and methods of the study. A pilot study with mixed ethnic participants was carried out in order to assure the clarity of the translated measures according to the recommended procedures for the establishment of linguistic equivalence (van de Vijver \& Leung, 1997). The pretest involved a total of 152 adolescents who were not included in the present study, and revealed good psychometric properties of the measures. For the present study, data were collected in a classroom setting during regular class hours for approximately 30-45 minutes. All measures were presented only in Bulgarian, because in the pilot study (in which versions in all languages were available) 
Table 1

Sample characteristics

\begin{tabular}{|c|c|c|c|}
\hline & $\begin{array}{l}\text { Turkish-Bulgarian } \\
\qquad(n=145)\end{array}$ & $\begin{array}{l}\text { Muslim-Bulgarian } \\
\qquad(n=85)\end{array}$ & $\begin{array}{l}\text { Bulgarian } \\
(n=136)\end{array}$ \\
\hline \multicolumn{4}{|l|}{ Age } \\
\hline Range & $16-18$ & $16-18$ & $16-18$ \\
\hline$M(S D)$ & $16.66(0.72)$ & $16.93(0.66)$ & $16.65(0.70)$ \\
\hline \multicolumn{4}{|l|}{ Gender } \\
\hline Boys & $83(57.20 \%)$ & $37(43.50 \%)$ & $80(58.80 \%)$ \\
\hline Girls & $62(42.80 \%)$ & $48(56.50 \%)$ & $56(41.20 \%)$ \\
\hline \multicolumn{4}{|l|}{ SES } \\
\hline Low & $116(82.30 \%)$ & $65(77.40 \%)$ & $39(28.70 \%)$ \\
\hline Middle & $24(17.00 \%)$ & $19(22.60 \%)$ & $62(45.60 \%)$ \\
\hline High & $1(0.70 \%)$ & - & $35(25.70 \%)$ \\
\hline
\end{tabular}

all Turkish-Bulgarian students chose the Bulgarian language version.

\section{MEASURES}

Sociodemographic Questionnaire. A short questionnaire included items about self-reported ethnicity and nationality, SES (occupation and education of both parents), gender, age, place of birth, and religious affiliation. SES was computed by using a composite score of both parental education (primary, secondary and university degree) and occupation (unskilled, semi-professional, professional job), coded into three levels of low, middle, and high SES.

Identity Status was measured with the Extended Version of the Objective Measure of Ego Identity Status (EOM-EIS; Bennion \& Adams, 1986) scale to assess the four identity statuses, using a six-point Likert scale from strongly disagree to strongly agree. The measure assesses Marcia's ego identity statuses diffusion, foreclosure, moratorium, and achievement in domains of study, religion, philosophical life-style, friendship, dating, and recreation. Sample items include "When it comes to religion I just haven't found anything that appeals and I don't really feel the need to look", "My ideas about men's and women's roles are identical to my parents'. What has worked for them will obviously work for me", "I've had many different friendships and now I have a clear idea of what I look for in a friend", "There's no single 'life style' which appeals to me more than another", "My parents know what's best for me in terms of how to choose my friends". Reliability indices of the scale for the present samples have been acceptable (i.e., achievement $\alpha=.70$ to $\alpha=.71$, diffusion $\alpha=.61$ to $\alpha=.68$, foreclosure $\alpha=.83$ to $\alpha=.77$, moratori- um $\alpha=.76$ to $\alpha=.79$ ), which has also been reported elsewhere (Adams, 1989; Schwartz, Adamson, Ferrer-Wreder, Dillon, \& Berman, 2006).

Measures of Ethnic, Familial, and Religious Identi$t y$. These identity measures have been developed in previous studies on samples of ethnic minority and mainstream youth in Europe to comprehensively assess their ethnic, familial, and religious identity (Dimitrova, Chasiotis, Bender, \& van de Vijver, 2013a, Dimitrova et al., 2014b, 2015). The identity scales were created by generating items following identity components of self-categorization, attachment, evaluation, importance, and behavioral involvement (Ashmore et al., 2004). The stems of the items were identical for each scale, with targets (ethnicity, family, and religion) varying per scale as explained in more detail below.

Ethnic Identity Scale. This measure investigates ethnic identity with a total of 42 items answered on a five-point Likert scale from completely disagree to completely agree. For the Turkish-Bulgarian group, the items referred to both Turkish and Bulgarian aspects of ethnic identity. Hence, the number of items varied between groups, with a total of 42 items in the Turkish-Bulgarian and 21 items for the Bulgarian and Muslim-Bulgarian youth, respectively. Sample items include "I consider myself Turkish [Bulgarian]", "I am proud to be a member of the Turkish [Bulgarian] community", and "I participate in Turkish [Bulgarian] cultural practices". Internal consistencies across groups were $\alpha=.88$ and $\alpha=.95$, respectively.

Familial Identity Scale. This scale adopted the same format as the ethnic identity scale and has been previously applied in research with ethnic minority groups in Eastern Europe (Dimitrova et al., 2013a, 2013b; Dimitrova et al., 2015). Examples of the 21 items are "I see problems of my family as my problems" and 
"I have a strong sense of belonging to my family". The internal consistencies ranged from $\alpha=.91$ to .93 .

The Religious Identity Scale developed for ethnic minority groups in Eastern Europe (Dimitrova et al., 2013a, 2013b; Dimitrova et al., 2015) is a 21-item scale that again adopted the previously reported format of ethnic and familial identity scales. Sample items were "Being part of my religious community has much to do with how I feel about myself" and "When I need help, I can count on my religious community" $(\alpha=.89$ to .96$)$.

The Satisfaction with Life Scale (SWLS; Diener, Emmons, Larsen, \& Griffin, 1985) was used to measure global life satisfaction via five items evaluated on a seven-point scale $(1=$ strongly disagree, 7 = strongly agree). Sample items include "In most ways my life is close to my ideal" and "I am satisfied with life" $(\alpha=.74$ to $\alpha=.77)$.

The Positive Affective Schedule (PA; Watson, Clark, \& Tellegen, 1988) was applied to measure ten positive (e.g., "enthusiastic, proud, active") mood descriptors; their occurrence during the past two weeks is rated on a five-point scale (ranging from very slightly to extremely) $(\alpha=.73$ to $\alpha=.90)$. In subsequent analyses, well-being represents the average standardized scores of SWLS and PA, as these scales were significantly correlated, $r(352)=.23, p<.001$.

\section{RESULTS}

\section{MEAN DIFFERENCES IN COLLECTIVE IDENTITY ASPECTS AND IDENTITY STATUSES}

Preliminary analyses tested for cross-cultural equivalence across groups. Structural equivalence was evaluated with Tucker's phi (above .90 was accept- able and above .95 excellent) (van de Vijver \& Leung, 1997) and checked by comparing each group's, factor solution. The values of Tucker's phi across groups ranged from 0.99 to 1.00 for identity statuses, from 0.95 to 1.00 for collective identity components, and from 0.99 to 1.00 for well-being measures. We can conclude that all groups showed very good structural equivalence and therefore can be compared.

In order to test our first hypotheses (more representation of minority rather than mainstream youth in moratorium and foreclosure statuses as well as stronger religious identity), we tested mean differences in identity components in a MANCOVA with group (three levels) as the independent factor, with age and SES as covariates, and the four scales denoting identity status, ethnic Bulgarian, familial, and religious identity as dependent variables. The univariate analyses revealed a significant group effect for each identity: achievement $(F(2,227)=12.91, p<.001$, $\left.\eta^{2}=.10\right)$, diffusion $\left(F(2,227)=66.30, p<.001, \eta^{2}=.37\right)$, foreclosure $\left(F(2,227)=72.54, p<.001, \eta^{2}=.39\right)$, moratorium $\left(F(2,227)=30.80, p<.001, \eta^{2}=.21\right)$, as well as Bulgarian $\left(F(2,227)=33.19, p<.001, \eta^{2}=.23\right)$, familial $\left(F(2,227)=25.93, p<.001, \eta^{2}=.19\right)$, and religious identity, $F(2,227)=3.25, p<.05, \eta^{2}=.03$ (see Table 2 ). Bonferroni post hoc comparisons revealed that Turkish-Bulgarian youth scored higher on achievement, diffusion, and foreclosure status but lower on moratorium status, Bulgarian, and familial identity than both Muslim-Bulgarian and Bulgarian youth. As predicted, both Turkish-Bulgarian and Muslim-Bulgarian minorities scored significantly higher on religious identity compared to their mainstream peers. In addition, within the Turkish-Bulgarian group, we ran a paired sample $t$ test to compare Turkish and Bulgarian components of ethnic identity. Results for the Turkish-Bulgarian group revealed that the Turkish

Table 2

Means and standard deviations for the sample

\begin{tabular}{lccc}
\hline & $\begin{array}{c}\text { Turkish-Bulgarian } \\
(n=145)\end{array}$ & $\begin{array}{c}\text { Muslim-Bulgarian } \\
(n=85)\end{array}$ & $\begin{array}{c}\text { Bulgarian } \\
(n=136)\end{array}$ \\
\hline $\begin{array}{l}\text { Identity, } M(S D) \\
\text { Achievement }\end{array}$ & $30.25(7.78)_{\mathrm{a}}$ & $26.04(4.81)_{\mathrm{b}}$ & $24.93(5.39)_{\mathrm{b}}$ \\
Diffusion & $16.67(5.04)_{\mathrm{a}}$ & $8.81(3.24)_{\mathrm{b}}$ & $10.19(4.02)_{\mathrm{b}}$ \\
Foreclosure & $19.16(6.41)_{\mathrm{a}}$ & $9.04(3.84)_{\mathrm{b}}$ & $11.00(4.64)_{\mathrm{b}}$ \\
Moratorium & $17.55(4.65)_{\mathrm{a}}$ & $23.95(5.21)_{\mathrm{b}}$ & $24.90(5.94)_{\mathrm{b}}$ \\
Collective, $M(S D)$ & $3.48(0.73)$ & & - \\
Turkish & $2.80(0.72)_{\mathrm{a}}$ & - & $3.85(0.62)_{\mathrm{b}}$ \\
Bulgarian & $3.71(0.69)_{\mathrm{a}}$ & $3.54(0.71)_{\mathrm{b}}$ & $4.36(0.48)_{\mathrm{b}}$ \\
Familial & $3.35(0.60)_{\mathrm{a}}$ & $4.38(0.51)_{\mathrm{b}}$ & $3.11(0.87)_{\mathrm{b}}$ \\
Religious & $3.36(0.71)_{\mathrm{a}}$ &
\end{tabular}

Note. Means with different subscripts differ significantly between ethnic groups. 
Table 3

Goodness-of-fit indexes for identity and well-being model

\begin{tabular}{lcccc}
\hline Model & $\chi^{2}$ & $d f$ & CFI & RMSEA \\
\hline Unconstrained & $19.01^{*}$ & 10 & .985 & .040 \\
Structural weights & $24.95^{*}$ & 14 & .975 & .046 \\
Structural intercepts & $27.12^{*}$ & 16 & .974 & .044 \\
\hline
\end{tabular}

Note. $\chi^{2}$ - chi square value; $\mathrm{df}$ - degrees of freedom; CFI - comparative fit index; RMSEA - root-mean-square error of approximation; ${ }^{*} p<.05$, selected model is in italics.

identity is more important than the Bulgarian identity $(t(141)=8.17, p<.001$, Cohen's $d=.93)$, which is in line with our prediction that ethnic heritage would be more salient than mainstream identity in minority group members.

\section{IDENTITY AND WELL-BEING}

In order to test our second hypothesis (the influence of identity components on well-being), we implemented a multigroup regression model in AMOS (Arbuckle, 2009). The model tested direct associations among identity status, ethnic, familial, and religious components, and well-being (a composite score of standardized SWLS and PA scores) across ethnic groups. The structural weights model showed a good fit, $\chi^{2}(14, N=366)=24.95, p=.035$, RMSEA $=.046$ and CFI $=.975$ (Table 3). As can be seen in Figure 1, the model supports our expectations regarding the relationship between collective identity domains and well-being of youth. Foreclosed, ethnic and familial identities were significantly and positively associated with well-being across all groups. The regression coefficients for these identity components indicate stronger contribution of mainstream culture, foreclosed status, and family to well-being of mainstream and minority youth, irrespective of their cultural background. Therefore, we can conclude that our second hypothesis on ethnic, familial, and religious identity as important correlates of well-being was met. Despite mean differences in identity statuses as well as collective identity components, we found that the relationship of identity and well-being is identical across all the ethnic groups.

\section{DISCUSSION}

This study aimed at advancing research in important, yet understudied minority groups in Eastern Europe by providing empirical evidence on our collective identity approach, which comprises the joint study of identity status, ethnic, familial, and religious identity, and well-being of Turkish-Bulgarian and Muslim-Bulgarian minority compared to mainstream Bulgarian youth. We found that identity components differ across ethnic groups and are differentially related to well-being.

\section{IDENTITY DIFFERENCES ACROSS ETHNIC GROUPS}

In our first hypothesis, we expected minority youth to more frequently hold a moratorium and foreclosed status than mainstreamers. This was partly confirmed by finding significantly higher scores on foreclosure in our Turkish-Bulgarian minority group than in the Bulgarian group. Our results are consistent with those of Schwartz et al. (2006), who reported that Hispanic Americans, who are high on family orientation, scored higher than White Americans on foreclosure. A similarly pronounced foreclosure status has also been found with Mexican, Hispanic, African, and Asian Americans compared to European American samples (Streitmatter, 1988). Scores on moratorium and foreclosed status in the Turkish-Bulgarian group were also lower than in the Muslim-Bulgarian group. We suggest that these findings can be understood by considering the strong family influence in

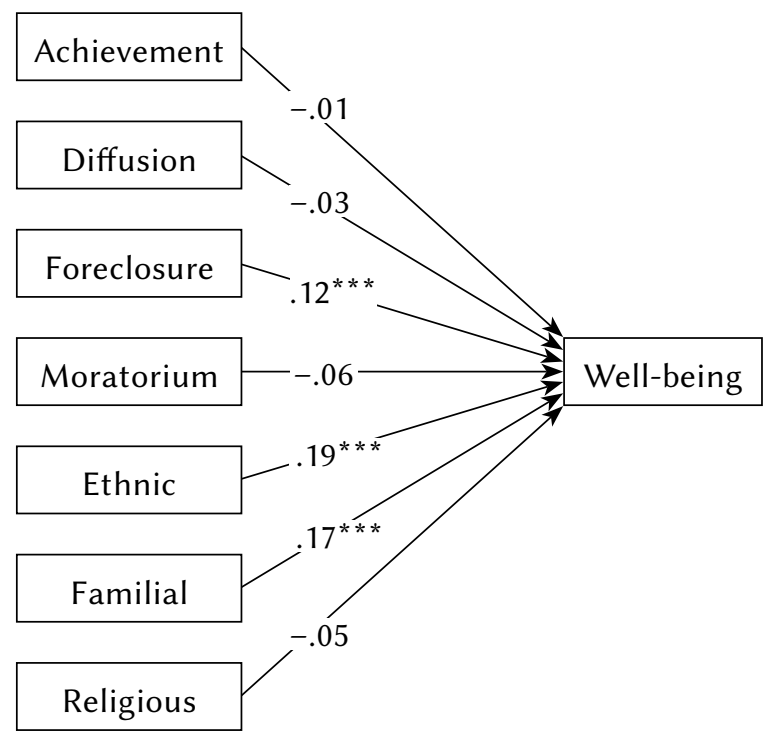

Note. Coefficients represent average standardized regression for all groups. ${ }^{* *} p<.001$.

Figure 1. Path model of identity domains and wellbeing across groups. 
the Turkish-Bulgarian minority. For Turkish-Bulgarian adolescents, identity status is strongly linked to their family and parental values. Also, for our Turkish-Bulgarians, the possibility to explore different identity alternatives may be confined by close family and intergroup relationships to a greater extent than in the Muslim-Bulgarian sample. Turkish-Bulgarians have a more widespread socioeconomic, political, and cultural network compared to the Muslim-Bulgarian community, which is less ethnically vital and tends to conform more to the mainstream culture (Dimitrova, Chasiotis, Bender, \& van de Vijver, 2012).

Moreover, Turkish-Bulgarian youth, Turkish identity was much stronger than their Bulgarian identity. It could well be that the relatively large distance to the Bulgarian mainstream culture facilitates the development of a Turkish identity. Our finding that Turkish identity is stronger than Bulgarian identity in our Turkish-Bulgarian participants is in line with research suggesting that a pronounced endorsement of ethnic identity may be a result of pressure to assimilate into the mainstream culture (Phinney, Horenczyk, Liebkind, \& Vedder, 2001) and hostility towards minority groups (Verkuyten \& Nekuee, 1999).

As expected, like Muslim-Bulgarians, TurkishBulgarians assigned a higher value to their religious identity than mainstream Bulgarian youth. Our data also suggest that Turkish-Bulgarian youth have an achieved identity status at an earlier age than their age mates from other ethnic groups. It appears that youth from the latter groups may struggle more to make identity choices. Such a unique identity is not available for the Muslim-Bulgarian group, which may be the reason why no aspect of collective identity is significantly stronger in this group than in the other groups. Past research has produced mixed findings, revealing no ethnic group differences in identity formation or showing that minority youth are more represented in the moratorium (Crocetti et al., 2008) and foreclosed status than mainstreamers (Spencer \& Markstrom-Adams, 1990). Our study clearly shows the importance of contextual factors in the development of identity. A good analysis of the status of a group and its relations with other ethnic groups is essential for the proper understanding of identity dynamics in any context.

\section{IDENTITY AND WELL-BEING}

Consistent with past research (Smith \& Silva, 2011), our results suggest that psychological well-being is affected by identity components across all ethnic groups. Our assumption that foreclosure rather than moratorium or diffusion statuses are related to well-being was confirmed. Foreclosed identity was related to well-being outcomes for all groups, in line with previous studies, indicating that adolescents with a foreclosure status reported having parents who strongly encourage the maintenance of their family values (Crocetti et al., 2008).

Our model further indicates that foreclosed status and ethnic and familial identities are related to well-being in a similar fashion across groups. These cross-group similarities suggest that despite mean differences in levels of identity endorsement, there are structural communalities underlying identity and well-being in all groups. In an earlier study it was found that the collective identity model proved to be applicable to youth from these very different groups (Dimitrova et al., 2012). The findings further support the notion of psychologically beneficial effects of identity in that a strong sense of ethnic and familial identity creates a sense of belonging which enhances well-being.

The lack of relationship between achieved identity, religious identity, and well-being is an interesting and unexpected finding. We reasoned that the context of acculturation has a critical importance in the study of these identity components of our groups. Identity and acculturation are influenced by relevant contextual factors. On one hand, we can assume that religious identity is likely to be weak and unrelated to well-being when members of minority groups experience a strong marginalization of their ethnic and religious traditions, which is the case for all Muslim communities in Bulgaria. On the other hand, it may well be that in a highly oppressive mainstream society, minority youth struggle with issues of identity achievement that do not lead to meaningful relationships with well-being. In a context of such marginalization and assimilation, these youth strongly endorse their ethnic and familial identity as a resource for psychological well-being.

\section{LIMITATIONS}

Our study has important methodological limitations. There is a potential for the collective identity approach to employ qualitative methods that would provide unique insights into identity complexity in adolescence. The use of measures of psychological health in relation to identity and discrimination (e.g., significant others or school reports) in future work may be beneficial for a clearer picture about how identity affects well-being of these youth. Although the EOM-EIS is still a widely accepted measure of identity during adolescence, a useful recommendation for future studies in identity research is to more closely look at the intermediate statuses (e.g., a reconsideration of commitment and in-depth exploration) (Crocetti et al., 2008). It is also worth mentioning that the reliability indices of the EOM-EIS scale have been in the marginal to acceptable range. This is a relevant shortcoming, which has also been reported in other 
international studies (Adams, 1989; Schwartz et al., 2006). Finally, our findings are limited to the Eastern European context. To what extent these finding may be generalized to other ethnic minority groups in other acculturating contexts warrants consideration in future research.

\section{CONCLUSIONS}

We see various strengths in the joint study of identity status and components of collective identity. The approach addresses the development status of identity as well as the most important components of collective identity. As the field of positive youth development enjoys tremendous interest among both scholars and policy makers, growing attention has been given to beneficial influences that shape developmental success. In this pursuit, both identity status and collective identity are relevant for well-being (Kiang, Yip, \& Fuligni, 2008). The idea behind our collective identity approach, amounting to an examination of identity status and domains that are relevant for the sense of coherence and belongingness, can be easily extended to other places. The finding that our approach works in relatively extreme acculturation conditions, as addressed in the present study, may well imply that it can also be used in cultural contexts with less adverse acculturation conditions. Finally, an advantage of the collective identity approach lies in its potential for stimulating developmental research in a more holistic direction by focusing on the multifaceted identity process in multi-level contexts (Ashmore et al., 2004). Our approach helps to establish an agenda for future research that addresses ethnic minority youth's identity within the context of fine-grained analyses of their multiple socialization experiences in increasingly diverse adolescent populations across cultures. Research adopting the collective identity approach can stimulate further insights into multifaceted identity components and advance our accurate understanding of today's culturally diverse and complex adolescent development.

This paper furthers our understanding of a novel collective identity approach in hardly investigated minority youth with a Turkish-Bulgarian and Muslim-Bulgarian background in Bulgaria. Our approach clearly shows the relevance of collective identity as a useful notion for the study of identity of minority youth with a diverse ethnic background in a post-communist European context. The major contribution of this study is the focus on these multiple identities and the need to pay close attention to contextual conditions on how youth identity is related to well-being. Among the practical implications of the study, useful indications for policy and practice are outlined. The beneficial effects of collective identity point to the importance of positive re- sources for well-being of youth. Future interventions and policies could include opportunities for these youth to enact their collective identity components such as familial cohesion, ethnic customs and traditions. Collective identity may be important not only for well-being, but also for salient ethnic differences among adolescents from minority groups, who independently of prolonged ethnic strife and assimilation are quite distinct from the mainstream Bulgarian culture. Therefore, adopting the collective identity approach may be useful in planning future research that addresses youth's identity in the Western European and American short-term immigration context.

\section{ACKNOWLEDGMENTS}

The authors are extremely grateful to Dr. Eva Jecheva and the National Agency for Child Protection and in all teachers and key staff (Neli Filipova, Ivanina Ivanova, Ivanina Noncheva, Radka Kostandinova, Albena Damianova, Stoyka Jekova, Svetla Atanasova, Neli Kiuchukova, Ani Angelova, Lilia Stoyanova, Tianka Kardjilova, Zvetan Terziev, Elena Ianeva, Venizslav Chobanov, Kamelia Mateva and Petko Petkov, Kircev, Gospova, Velianova, Chergova, Stamatov, Hristova, Kukusheva, Ahrianova, Bashev, Valcheva) for their help in carrying out the study.

\section{REFERENCES}

Adams, G. R. (1989). The Objective Measure of Ego Identity Status: A reference manual. Unpublished manuscript. University of Guelph, Canada.

Arbuckle, J. (2009). Amos 19. Crawfordville, FL: AMOS Development Corporation.

Ashmore, R. D., Deaux, K., \& McLaughlin-Volpe, T. (2004). An organizing framework for collective identity: Articulation and significance of multidimensionality. Psychological Bulletin, 130, 80-114. doi: 10.1037/0033-2909.130.1.80

Aydinli, A., \& Dimitrova, R. (2015). The dark side of multiple identities among Turkish-Bulgarian and Turkish-German adolescents. Journal of Adolescence. Advanced online publication. doi: 10.1016/j. adolescence.2015.09.010

Bagger, J., Li, A., \& Gutek, B. (2008). How much do you value your family and does it matter? The joint effects of family identity salience, family-interference with work, and gender. Human Relations, 6, 187-211. doi: 10.1177/0018726707087784

Bartkowski, J. P., Xu, X., \& Levin, M. L. (2008). Religion and child development: Evidence from the Early Childhood Longitudinal Study. HYPERLINK "http://www.sciencedirect.com/science/journal/0049089X” Social Science Research, 37, 18-36. 
Bennion, L. D., \& Adams, G. R. (1986). A revision of the extended version of the Objective Measure of Ego Identity Status: An identity instrument for use with late adolescents. Journal of Adolescent Research, 1, 183-198. doi: 10.1177/074355488612005

Berman, S. L., Weems, C. F., \& Stickle, T. R. (2006). Existential anxiety in adolescents: Prevalence, structure, association with psychological symptoms and identity development. Journal of Youth and Adolescence, 35, 303-310. doi: 10.1007/s10964006-9032-y

Branch, C. W., Tayal, P., \& Triplett, C. (2000). The relationship of ethnic identity and ego identity status among adolescents and young adults. International Journal of Intercultural Relations, 24, 777-790. doi: 10.1016/S0147-1767(00)00031-6

Cleveland, M. J., Feinberg, E., \& Greenberg, M. T. (2010). Protective families in high- and low-risk environments: Implications for adolescent substance use. Journal of Youth and Adolescence, 39, 114-126. doi: 10.1007/s10964-009-9395-y

Costigan, C. L., Koryzma, C. M., Hua, J. M., \& Chance, L. J. (2010). Ethnic identity, achievement, and psychological adjustment: Examining risk and resilience among youth from immigrant Chinese families in Canada. Cultural Diversity and Ethnic Minority Psychology, 16, 264-273. doi: 10.1037/ a0017275

Crocetti, E., Fermani, A., Pojaghi, B., \& Meeus, W. (2011). Identity formation in adolescents from Italian, mixed, and migrant families. Child Youth Care Forum, 40, 7-23. doi: 10.1007/s10566-010-9112-8

Crocetti, E., Rubini, M., Luyckx, K., \& Meeus, W. (2008). Identity formation in early and middle adolescents from various ethnic groups: From three dimensions to five statuses. Journal of Youth and Adolescence, 37, 983-996. doi: 10.1007/s10964-007-9222-2

Diener, E., Emmons, R. A., Larsen, R. J., \& Griffin, S. (1985). The Satisfaction with Life Scale. Journal of Personality Assessment, 49, 71-75. doi: 10.1207/ s15327752jpa4901_13

Diener, E., Lucas, R. E., \& Scollon, C. N. (2006). Beyond the hedonic treadmill: Revisions to the adaptation theory of well-being. American Psychologist, 61, 305-314. doi: 10.1037/0003-066X.61.4.305

Dimitrov, V. (2000). In search of a homogeneous nation: The assimilation of Bulgaria's Turkish minority, 1984-1985. European Center for Minority Issues Report, Flensburg, Germany.

Dimitrova, R., Aydinli, A., Chasiotis, A., Bender, M., \& van de Vijver, F. J. R. (2015). Ethnic identity and acculturation enhance well-being of Turkish-Bulgarian and Turkish-German adolescents. Social Psychology. doi: 10.1027/1864-9335/a000230

Dimitrova, R., Chasiotis, A., Bender, M., \& van de Vijver, F. J. R. (2014a). From a collection of identities to collective identity: Evidence from mainstream and minority adolescents in Bul- garia. Cross Cultural Research, 48, 339-367. doi: 10.1177/1069397114523922

Dimitrova, R., Chasiotis, A., Bender, M., \& van de Vijver, F. J. R. (2014b). Turks in Bulgaria and the Netherlands: A comparative study of their acculturation orientations and outcomes. International Journal of Intercultural Relations, 40, 76-86. doi: 10.1016/j.ijintrel.2014.01.001

Dimitrova, R., Chasiotis, A., Bender, M., \& van de Vijver, F. J. R. (2012). Ethnic identity and acculturation of Turkish-Bulgarian adolescents. International Journal of Intercultural Relations, 37, 1-10. doi: 10.1016/j.ijintrel.2012.04.005

Dimitrova, R., Chasiotis, A., Bender, M., \& van de Vijver, F. J. R. (2013a). Collective identity and well-being of Roma adolescents in Bulgaria. International Journal of Psychology. doi: org/10.1080/00 207594.2012.682064

Dimitrova, R., Chasiotis, A., Bender, M., \& van de Vijver, F. J. R. (2013b). Collective identity of Bulgarian Roma adolescents and mothers. Journal for Youth and Adolescence, 43, 375-386. doi: 10.1007/ s10964-013-0043-1

Erikson, E. (1968). Identity: Youth and crisis. New York, NY: Norton.

Furrow, J. L., King, P. E., \& White, K. (2004). Religion and positive youth development: Identity, meaning, and prosocial concerns. Applied Developmental Science, 8, 17-26. doi: 10.1207/S1532480XADS0801_3

Georgas, J., Berry, J. W., van de Vijver, F. J. R., Kagitcibasi, C., \& Poortinga, Y. H. (eds.). (2006). Families across cultures. A 30-nation psychological study. Cambridge, United Kingdom: Cambridge University Press.

Ghavami, N., Fingerhut, A., Peplau, L., Grant, S. K., \& Witting, M. A. (2011). Testing a model of minority identity achievement, identity affirmation, and psychological well-being among ethnic minority and sexual minority individuals. Cultural Diversity and Ethnic Minority Psychology, 17, 79-88. doi: 10.1037/a0022532

Halman, L. C. J. M., \& Petterson, T. (2001). Religion and social capital in contemporary Europe. Results from the 1999/2000 European Values Study. In D. O. Moberg \& R. L. Piedemont (eds.), Research in the social scientific study of religion (pp. 65-94). Leiden, the Netherlands: Brill.

Kiang, L., Yip, T., \& Fuligni, A. J. (2008). Multiple social identities and adjustment in young adults from ethnically diverse backgrounds. Journal of Research on Adolescence, 18, 643-670.

Konstantinov, Y., Alhaug, G., \& Igla, B. (1991). Names of the Bulgarian Pomaks. Nordlyd: Tromso University working papers on language and linguistics.

Kroger, J., \& Marcia, J. E. (2011). The identity statuses: Origins, meanings, and interpretations. In S. J. Schwartz, K. Luyckx, \& V. L. Vignoles (eds.), Hand- 
book of identity theory and research (pp. 31-53). New York: Springer.

Lopez, A. B., Huynh, V. W., \& Fuligni, A. J. (2011). A longitudinal study of religious identity and participation during adolescence. Child Development, 82, 1297-1309. doi: 10.1111/j.1467

Lucas, R. E, Diener, E., \& Suh, E. (1996). Discriminant validity of well-being measures. Journal of Personality and Social Psychology, 71, 616-628. doi: 10.1037/0022-3514.71.3.616

Luyckx, K., Goossens, L., Soenens, B., Beyers, W., \& Vansteenkiste, M. (2005). Identity statuses based upon four rather than two identity dimensions: Extending and refining Marcia's paradigm. Journal of Youth and Adolescence, 34, 605-618. doi: 10.1007/s 10964-005-8949-x

Marcia, J. E. (1980). Identity in adolescence. In J. Adelson (ed.), Handbook of adolescent psychology (pp. 159-187). New York, NY: Wiley.

National Statistics Institute (NSI). (2011). Census 2011. Sofia, Bulgaria: NSI Press.

Nesbitt, E., \& Arweck, E. (2010). Issues arising from an ethnographic investigation of the religious identity formation of young people in mixed-faith families. Fieldwork in Religion, 5, 7-30.

Phinney, J. S. (1989). Stages of ethnic identity development in minority group adolescents. Journal of Early Adolescence, 9, 34-49. doi: 10.1177/ 0272431689091004

Phinney, J. S. (1990). Ethnic identity in adolescents and adults: Review of research. Psychological Bulletin, 108, 499-514. doi: 10.1037/00332909.108.3.499

Phinney, J. S., Horenczyk, G., Liebkind, K., \& Vedder, P. (2001). Ethnic identity, immigration, and well-being: An interactional perspective. Journal of Social Issues, 57, 493-510. doi: 10.1111/00224537.00225

Phinney, J. S., \& Ong, A. D. (2007). Conceptualization and measurement of ethnic identity: Current status and future directions. Journal of Counselling Psychology, 54, 271-281. doi: 10.1037/00220167.54.3.271

Rivas-Drake, D., Syed, M., Umaña-Taylor, A. J., Markstrom, C., French, S., Schwartz, S. J., Lee, R. M., \& Ethnic and Racial Identity Study Group. (2014). Feeling good, happy, and proud: A meta-analysis of positive ethnic-racial affect and adjustment. Child Development, 85, 77-102. doi: 10.1111/ cdev. 12175

Schwartz, S. J., Adamson, L., Ferrer-Wreder, L., DilIon, F. R., \& Berman, S. L. (2006). Identity status measurement across contexts: Variations in measurement structure and mean levels among White American, Hispanic American, and Swedish emerging adults. Journal of Personality Assessment, 86, 61-76.
Schwartz, S. J., Luycks, K., \& Vignoles, V. L. (2011). (eds.). Handbook of Identity Theory and Research. New York, NY: Springer.

Schwartz, S. J., Zamboanga, B. L., Weisskirch, R. S., \& Rodriguez, L. (2009). The relationships of personal and ethnic identity exploration to indices of adaptive and maladaptive psychosocial functioning. International Journal of Behavioral Development, 33, 131-144. doi: 10.1177/0165025408098018

Smith, T. B., \& Silva, L. (2011). Ethnic identity and personal well-being of people of color: A meta-analysis. Journal of Counseling Psychology, 58, 42-60. doi: 10.1037/a0021528

Spencer, M. B., \& Markstrom-Adams, C. (1990). Identity processes among racial and ethnic minority children in America. Child Development, 61, 290310. doi: $10.2307 / 1131095$

Srebranov, R. (2006). Bulgarian Muslims from the Chech region and their linguistic self-identification. International Journal of Sociology of Language, 179, 131-143. doi: 10.1515/IJSL.2006.030

Streitmatter, J. (1988). Ethnicity as a mediating variable of early adolescent identity development. Journal of Adolescence, 11, 335-346. doi: 10.1016/ S0140-1971(88)80033-2

Tajfel, H., \& Turner, J. (2001). An integrative theory of intergroup conflict. In M. A. Hogg \& D. Abrams (eds.), Relations: Essential readings. Key readings in social psychology (pp. 94-109). New York, NY: Psychology Press.

Turner, J. C., Hogg, M. A., Oakes, P. J., Reicher, S. D., \& Wetherell, M. S. (1987). Rediscovering the social group: A self-categorization theory. Oxford, United Kingdom: Blackwell.

Udel, W., Donenberg, G., \& Emerson, E. (2011). The impact of mental health problems and religiosity on African-American girls' HIV-risk. Cultural Diversity and Ethnic Minority Psychology, 17, $217-$ 224. doi: $10.1037 / \mathrm{a} 0023243$

Van de Vijver, F. J. R., \& Leung, K. (1997). Methods and data analysis for cross-cultural research. Thousand Oaks, CA: Sage.

Vazsonyi, A. T., \& Pickeirng, L. E. (2003). The importance of family and school domains in adolescent deviance: African American and Caucasian youth. Journal of Youth and Adolescence, 32, 115-128. doi: 10.1023/A:1021857801554

Verkuyten, M., \& Nekuee, S. (1999). Subjective well-being, discrimination and cultural conflict. Iranians living in the Netherlands. Social Indicators Research, 47, 281-306. doi: 10.1023/A:1006970410593

Verkuyten, M., \& Yildiz, A. A. (2009). Muslim immigrants and religious group feelings: Self-identification and attitudes among Sunni and Alevi Turkish-Dutch. Ethnic and Racial Studies, 32, 1121-1142. doi: 10.1080/01419870802379312

Wallace, J. M., Forman, T. A., Caldwell, C. H., \& Willis, D. S. (2003). Religion and U.S. secondary school 
students: Current patterns, recent trends, and sociodemographic correlates. Youth and Society, 35, 98-125. doi: 10.1177/0044118X03254564

Watson, D., Clark, L. A., \& Tellegen, A. (1988). Development and validation of brief measures of positive and negative affect: The PANAS scales. Journal of Personality and Social Psychology, 54, 1063-1070. doi: 10.1037/0022-3514.54.6.1063

Watson, M. F., \& Protinsky, H. (1991). Identity status of Black adolescents: An empirical investigation. Adolescence, 26, 963-966.

Yap, S. C. Y., Settles, I. H., \& Pratt-Hyatt, J. S. (2011). Mediators of the relationship between racial identity and life satisfaction in a community sample of African American women and men. Cultural Diversity and Ethnic Minority Psychology, 17, 8997. doi: $10.1037 / \mathrm{a} 0022535$ 